\title{
Reflections on the Involvement of Design Education in Basic Education
}

\author{
Xiao Zhang1, \\ ${ }^{1}$ Anshun University, Anshun, Guizhou, 561000
}

Keywords: Design Education, Design Thinking, Basic Education

\begin{abstract}
Fine arts education focuses on cultivating students' aesthetic expressions and skills. It is hoped that students can establish basic knowledge of arts. The design education focuses on the students' design thinking and creation in the constraints. Design education can become a good form of thinking, involved in basic education.
\end{abstract}

\section{Introduction}

Three years ago, I once took students with a survey on the status quo of art education in primary schools in Anshun City. It was found that primary schools in the suburbs and the suburbs of the city were generally equipped with 3-5 full-time art teachers, which basically could meet the elementary school art curriculum. Opened and organized interest groups to carry out various after-school activities. After three years of development, this allocation of teachers further covered the more remote township primary schools. In the past, the state of distress in primary school art teachers was basically changed. When we continue to take college internships to help these primary schools, I think we can also help? What difference can we bring in addition to a few fresh faces?

Some time ago I happened to see a design education program "Design あ" ("Ah! Design") of a Japanese NHK TV station. This program carries a "designed mentality, everyone must have" point of view for Japanese children. Play. Although it is child-oriented, it has a unique perspective and is full of inspiration for thinking. Each episode also invites heavyweight designers to tell the secrets of design. Naoto Fukasawa, Barbara Masayoshi, grandfather Jiang Shen, and Toyo Ito are all guests of the show. When I watched this program, I immediately felt that I had a good time. Why can we not involve design education in our basic education?

\section{Design Education is the Training of Way of Thinking}

One of the domestic references to thinking science is more recognized is Mr. Qian Xuesen. He divides human thinking into logical thinking, visual thinking and creative thinking. He believes that "creative thinking is the source of wisdom; both logical thinking and visual thinking are It is a means "1.

Logical thinking trains people's reasoning ability. "It is abstract thinking as the basic thinking method and language and symbol as the basic expression tool's thinking form.” 1 It is also called abstract thinking. We can usually judge based on the existing information. For example, the difference between pottery and porcelain is that the materials used are clay and kaolin. The firing temperature is 800 degrees and 1200 degrees. The pottery is not glazed and the porcelain is glazed. Therefore, we can judge that the teapot is pottery, but when we judge Tang Sancai, we Misunderstandings will arise. When we conduct logical reasoning, there will be situations where reality and experience are at odds. At this time, there may be cases where experience dominates and the mindset is established.

"Art is an intuitive observation of the truth, or is the use of images to think." 2. Belinsky thinks that artists use images and graphics to think. This is the earliest mention of image thinking. Image thinking usually requires people to think through association and imagination, and process specific information according to some vague, typical, and general images. For example, Chinese painting pays attention to the artistic conception. This kind of artistic conception is more often felt through the blankness in paintings. Another example is that the sheep is beautiful and the image of people 
will naturally make up the image of a fat sheep.

Creative thinking was proposed by the Gestalt Psychology School. Wertheim defined the thinking as the process of problem solving in his book "Creative Thinking”. He thought that there were two problems, one was a normative problem, and it was through the canonical calculation. The answer is the answer, and the other is the question of ambiguity as artistic creation. It is the preferred process for alternatives3.

"Design thinking is a kind of creative thinking. It has non-continuous and jumping characteristics." 4. Marx also described the image of the design activity: "The most crappy architect from the outset was better than the smartest bees in that he built it in his own mind before building it with beeswax. The results obtained at the end of the process have already existed in the appearance of the laborers at the beginning of the process, that is, they have been conceptually existing." 5 The process of design thinking is usually a screening of many alternatives. The design thinking is radioactive. Way of thinking.

In the past art education, we focused on cultivating students' aesthetic expressions and skills training. We hope that students can establish basic understanding of beauty. The design education focuses on the students' design thinking and creates in the constraints.

\section{Design Education in Basic Education}

Design education cultivates students' creativity and encourages them to boldly express their own ingenious ideas and critical opinions. This also requires students to have a comprehensive quality of curiosity, courage, autonomy, and honesty. When design education enters primary and secondary schools, I want to be able to train from everyday life ideas.

Observation, extensive observation, close observation, observation at different angles. Experience those things in life that make people "become awkward", such as its shape, touch, smell, sound, details, etc., consider the relationship with people, the feelings of people, and translate into language. Ask questions often why it is convenient or inconvenient to use. The use of imagination to transform everyday objects can be based on nature or the transformation of items, such as the conversion of Muji's record players and exhaust fans. Do something that everyone does not do.

Tracing the source, thinking from the relationship between functions and people or the environment, it is appearance. For example, a lamp, first consider the need for light and shadow to design the location, shape, material and so on. For example, a chair can think of all the people's use of action, according to the lean, hanging action plus comfortable wide chair back. Another example is a kettle, which can be considered to improve the design of the spout to make the water more convenient or to meet the different needs of the water, and it can be found, added or improved.

A thing can be expressed in many ways. For example, find a Chinese character arbitrarily and interpret it in various ways, package items in life, etc., in which multiple dimensions such as shape, material, color, and combination modes may be simply visually diversified, such as fonts and foods. The design is only an aesthetic function; perhaps there are more functional needs, such as package or packaging design must consider the shape of the packaged items, handheld methods and so on.

Dismantling and refactoring. Understand the structure of the objects; abstract the objects into shapes, get more possibilities, and have more perspectives than the plane, such as side, top, and section.

Observe the daily movement of the human body. The same action can be used on different items, such as why the design of the mineral water bottle cap is rotated rather than pressed; different actions can be gathered in the same article to develop different uses, such as smashing, cutting, pressing, painting, stirring, smashing, etc. Actions are used to make the above difference in food production.

Observe the different shapes of life. Daily things such as brick walls, flowers, clocks, and city buildings can be abstracted as circles, squares, triangles, polygons, or their combinations. The characteristics of geometry can be reflected in the difference in visual performance, and more can be the difference in response function. For example, the radius of the glasses does not have a functional difference, and only aesthetic considerations may be considered. The balls, sink plugs, 
and scissors handles have a round shape because the circles are good at rolling, turning, focusing, and penetrating; bookshelf, brick walls, and TV screens have a lot of squareness because Square is good at segmentation, mosaic, neatly arranged and conveyed.

Find the best solution in daily life design. Use the methods of backward push and unrestrained transformation to rethink the products that have become habits in life, rediscover the inconveniences, and then step by step to improve the optimal solution. For example, why the design of the book is not a repetitive folding of strips, why the roadmap The design symbol cannot be text or other gestures.

\section{Conclusion}

The way of thinking is always an important link in basic education, and the way of designing education happens to be a very good medium for thinking training. Therefore, design education in basic education can not only train students' thinking methods, but also It can improve the foundation of Chinese intellectual creation.

On the basis of the existing conditions, it is very difficult to achieve full coverage of design education, and it can be promoted from the process of helping and supporting universities. From the beginning of small activities, the influence of teachers and students in primary and secondary schools was increased, and the frequency of helpers gradually increased, and then the design consciousness in basic education was fully stimulated.

\section{References}

[1] Chief Editor Zhao Guangwu. Thinking Science Research [M]. Renmin University of China Press, (1999): 12 14

[2] Russian Belynsky. Mantao. The concept of art [M]. Shanghai Translation Publishing House, (1980): 93

[3] De Wittheim, Lin Zongji, Translation. Creative Thinking[M]. Educational Science Press, (1987): 220 225

[4] Li Yuzu. An Introduction to Design Art [M]. Hubei Fine Arts Publishing House, (2002): 174

[5] Russia, Marx, Capitalism [M]. People's Publishing House, (1972): 202 